\title{
CXCL1-CXCR2 axis mediates neutrophils recruitment in rat oral mucosa
}

\author{
Tong $\mathrm{Wu}^{{ }^{*}}$, Hong Wang ${ }^{1 *}$, Yulei Huang ${ }^{1}$, Yaohui Dai ${ }^{1}$, Wenxin $\mathrm{Zuo}^{2}$, Lihua Jia ${ }^{1}$, Bin Cheng ${ }^{1 \#}$ \\ ${ }_{1}^{1}$ Department of Oral Medicine, Guanghua School of Stomatology, Sun Yat-sen University, Guangzhou, China \\ ${ }^{2}$ Department of Stomatology, Jinan University 2nd Clinical Medicine College, Shenzhen People's Hospital, Shenzhen, China \\ Email: " chengbin@mail.sysu.edu.cn
}

Received 25 October 2013; revised 26 November 2013; accepted 6 December 2013

Copyright (C) 2013 Tong Wu et al. This is an open access article distributed under the Creative Commons Attribution License, which permits unrestricted use, distribution, and reproduction in any medium, provided the original work is properly cited.

\begin{abstract}
A lot of researches have shown that besides acting as essential contributors in innate immune response, neutrophils involved in the interaction between innate and adaptive immune responses by generation of a cascade of chemokines. But the data on relationship between chemokines and neutrophils recruitment in oral mucosa have been little available. In the present study, on a rat model characterized by neutrophils infiltration, a distinct profile of cytokines and receptors in oral mucosa was presented by the techniques of PCR array. Moreover, among these cytokines, upexpression of CXCL1 and its receptor, CXCR2, was found to correlate with the level of myeloperoxidase (MPO), a biomarker of neutrophils infiltration, and the up-expression of CXCL1-CXCR2 was suppressed by FK506, an immunosuppressive agent. Our results indicated that CXCL1-CXCR2 axis might play an important role in mediating neutrophils recruitment in oral mucosa, which will give new insights into the mechanisms of innate and adaptive immune responses of oral mucosa.
\end{abstract}

Keywords: Neutrophils; Recruitment; CXCL1; CXCR2; Oral Mucosa

\section{INTRODUCTION}

Neutrophils are essential innate immune cells and major contributors to inflammation. Besides acting as indispensable mediators for defense against intruding microorganisms in innate immune response, neutrophils involve in the interaction between innate and adaptive immune response by communicating with adaptive immune cells such as $\mathrm{T}$ cells via generation of a cascade of che-

\footnotetext{
*Tong $\mathrm{Wu}$ and Hong Wang contribute equally in this manuscript.

\#Corresponding author.
}

mokines [1,2]. Together with their receptors expressed on leukocytes, chemokines are chemotactic cytokines, which play a crucial role in the extravasation and migration of leukocytes under inflammatory conditions [3]. However, the scenario of chemokines in oral mucosal inflammatory milieu, which associated with neutrphils recruitment and further interaction with adaptive immune cells, is largely unknown.

Among the cytokines highlighted in mediating neutrophils recruitment, several lines of study have emphasized the importance of CXCL1-CXCR2 axis in a series of inflammatory diseases, including adenoviral keratitis, hemolytic transfusion reactions, rhinovirus infection induced neutrophilic airway inflammation, autoantibodymediated arthritis and cortical damage following closed head injury [4-8]. But the evidences on CXCL1-CXCR2 axis' involvement in inflammatory-autoimmune disorders of oral mucosa have been little available yet. Therefore, the aim of the present study was to disclose the correlation between expression of CXCL1-CXCR2 axis and neutrophils infiltration in a rat model of oral mucosal xenotransplantation characterized by neutrophils infiltration which has been reported [9], hoping to give some new clues on the mechanisms of neutrophils recruitment to oral mucosa in inflammatory-autoimmune disorders.

\section{MATERIALS AND METHODS}

\subsection{Animals}

Female Wistar rats weighing $160 \mathrm{~g}-180 \mathrm{~g}$ as recipients and female Balb/C mice weighing $18 \mathrm{~g}-20 \mathrm{~g}$ as donors were purchased and maintained in the Center of Experimental Animals of Sun Yat-sen University (Guangzhou, China). The study was approved by the Animal Use and Care Committees of Sun Yat-sen University. The animals were acclimated for at least 1-week prior to use in these experiments. 


\subsection{Animal Model}

Oral mucosal xenotransplant rat model was established as previous described by our group [9]. Briefly, after being intraperitoneally anesthesized with chloral hydrate, full tongue tissue of $0.3-0.5 \mathrm{~cm}$ length from $\mathrm{Balb} / \mathrm{C}$ mice was transplanted under the left buccal mucosa of Wistar rat (xenotransplantation group, X). Rats received similar surgical procedures but without embedding tongue tissues (trauma group, $\mathrm{T}$ ) and rats received no surgical procedures (control group, C) were assigned as trauma and normal controls, respectively.

\subsection{FK506 Treatment of Rats}

Treatment with tacrolimu, namely FK506 (Fujisawa Pharmaceutical Co, Toyama, Japan) was started three days before surgery for 3 consecutive days with high doses of $2 \mathrm{mg} / \mathrm{kg} /$ day orally and continued with low doses of $0.5 \mathrm{mg} / \mathrm{kg} /$ day for 7 consecutive days after surgery [9]. Rats received FK506 treatment and xenotransplantation, trauma and normal control were assigned as FK506 treated xenotransplantation group (FX), FK506 treated trauma group (FT) and FK506 treated control group (FC) respectively.

\subsection{Buccal Sample Collection and RNA Isolation}

All rats were observed daily for up to 30 days. Five groups of buccal samples (three rats per group) from $\mathrm{X}$, $\mathrm{T}$ group (sacrificed at $7 \mathrm{~d}$ and $30 \mathrm{~d}$ after operation respectively) and $\mathrm{C}$ group were collected. Whole buccal tissues of rats were isolated and collected for PCR array analysis. Total RNA was extracted with Trizol reagent (Invitrogen, Gaithersburg, MD, USA) according to the manufacturer's instructions. The RNA quality was assessed by formaldehyde agarose gel electrophoresis and quantitated spectrophotometrically. The mRNA sample for chip hybridization was prepared by mixing the mRNA samples of every rat from the same group in equal quantities.

\subsection{Buccal Sample Collection and Protein Isolation}

All rats were observed daily for up to 30 days. Six rats per group from X, T, C, FX, FT and FC group were sacrificed at $7 \mathrm{~d}$ and $30 \mathrm{~d}$ after operation respectively. The buccal tissues (about $300 \mathrm{mg}$ ) were triturated in liquid nitrogen and homogenized in $2 \mathrm{ml}$ cold PBS $(\mathrm{pH} 7.4$, $0.01 \mathrm{M}$ ), using a high-speed homogenizer (Scientz Biotechnology Co., Ningbo, China). The samples of homogenate were submitted to $10,000 \mathrm{~g}$ speed centrifugation for $5 \mathrm{~min}$ at $4^{\circ} \mathrm{C}$. Then supernatants were divided into 0.1 $\mathrm{ml}$ aliquots, and stored at $-80^{\circ} \mathrm{C}$ until used for measurement of total protein and enzyme-linked immunosorbent assay (ELISA) analysis.

\subsection{RT2 Profiler PCR Array for Rat Cytokines and Receptors}

Total RNA $(20 \mu \mathrm{g})$ from buccal sample was converted to cDNA and used to screen inflammatory cytokines and receptors using Rat Inflammatory Cytokines \& Receptors PCR Array

(http://www.sabiosciences.com/rt per product/HTML/P ARN-011A.html) according to manufactuer's instructions (SABiosciences, Frederick, MD, US). The acquired data were analyzed using the $\Delta \Delta \mathrm{CT}$ method to determine the expression of each transcript normalized to the expression of housekeeping gene controls. A gene-wise, two-sample, t-test was done for each transcript to identify statistical differences in expression between $\mathrm{X}, \mathrm{T}$ and $\mathrm{C}$ group respectively. A 2-fold or greater change was determined to be the threshold cut-off point for what is considered a change in gene expression in this study.

\subsection{Quantitative Real-Time PCR}

Rat buccal RNA preparations used for the PCR array were also subjected to real-time PCR assays using primers specific for CXCL1 and CXCR2 genes. The primer sets for these genes were designed to amplify about 100 bp segments and primers specific for $\beta$ actin were used as a house keeping gene control. All primers were customdesigned from GenBank mRNA sequences and prepared by DaAn Gene Company (Guangzhou, China). PCR primer sequences are as follows: for CXCL1, F:5'CCAAACCGAAGTCATAGCCA3' and R:5'CACCCTTTAGCATCTTTTGGA3'; for CXCR2, F:5'CCATCTTCATTCTTCGGACT3' and R:5'AACAGGACAATGTTGTAGGGA3'; for $\beta$ actin, F:5'CCTGTACGCCAACACAGTGC3' and R:5'ATACTCCTGCTTGCTGATCC3'. cDNA was synthesized from $4 \mu \mathrm{g}$ RNA samples using oligo dT to prime the reverse transcriptase reaction. RT-PCR was carried out on the ABI 9700 instrument (ABI company, Foster City, CA, USA) with the QPCR SYBR green detection reagent (ABI company, Foster City, CA, USA) for $3 \mathrm{~min}$ at $95^{\circ} \mathrm{C}$ for the initial denaturing, followed by 40 cycles of $95^{\circ} \mathrm{C}$ for 2 minute, $60^{\circ} \mathrm{C}$ for 20 seconds and $99^{\circ} \mathrm{C}$ for 15 seconds. Cell threshold values for each gene were determined and fold induction compared with $\beta$ actin were calculated using the $\Delta \Delta \mathrm{CT}$ method. PCR products were evaluated by dissociation curves to confirm single amplication and the absence of significant primer-dimer contamination.

\subsection{ELISA Analysis}

Total protein from rat buccal tissue was quantified using a BCA Protein Assay Kit (Pierce Inc., Rockford, IL, USA) as our previous description [10]. The concentrations of CXCL1, CXCR2 and myeloperoxidase (MPO) 
in supernatant of tissue were determined by using ELISA kits (Alpco Diagnostics, New Hampshire, USA), according to the manufacturer's protocol. Colorimetric optical density was read at $450 \mathrm{~nm}$ and a standard curve was generated from a plot of optical density versus the $\log$ of the concentration of standard. The concentration of CXCL1, CXCR2 and MPO in tissue was expressed as the ratio of CXCL1,CXCR2 and MPO concentration to total protein in order to take into account slight differences of tissue weights. So the level of CXCL1, CXCR2 and MPO was presented as ng/mg in tissues. ELISA and total protein assays were done in duplicate and the result for each sample was the mean of the 2 tests. The levels of both cytokines were presented as $\mathrm{pg} / \mathrm{mg}$ (the ratio of cytokine concentration to total protein) in tissues, as previously described [11].

\subsection{Statistical Analysis}

Data collection and statistical analysis were performed using SPSS 13.0 statistical software (SPSS Inc, Chicago, IL, USA). All data are presented as the mean \pm SD of triplicate determinations. The data were analyzed by ANOVA followed by Bonferroni's method for multiple

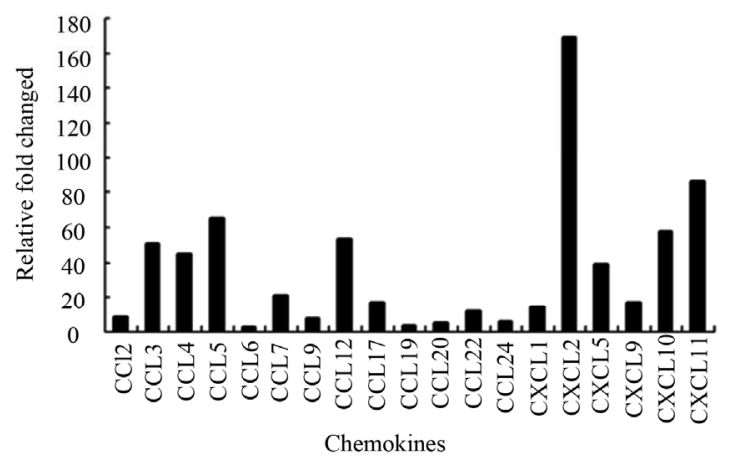

(a)

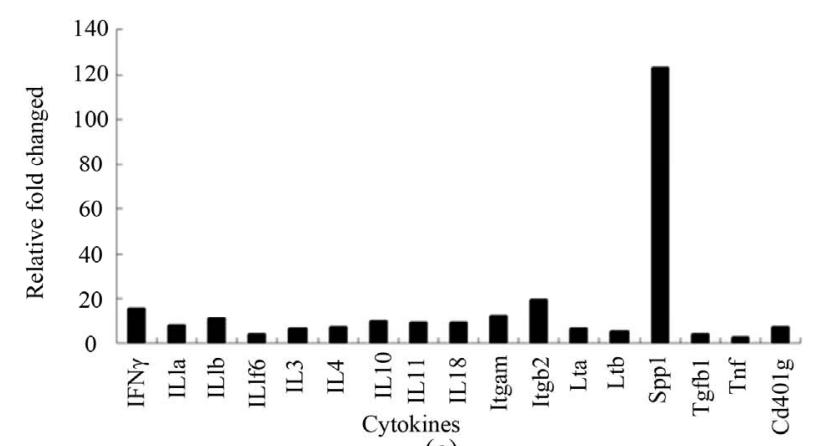

(c) comparisons between pairs. $\mathrm{P}<0.05$ was considered to be significant. Association levels were assessed by spearman correlation coefficient. Probability value of $\mathrm{P}<0.05$ was considered as statistically significant for all statistical test carried out. Each experiment was repeated three times with similar results.

\section{RESULTS}

\subsection{The Distinct Profile of Inflammatory Cytokines and Receptors during Neutrophils Infiltration in Oral Mucosa}

Five groups of samples from two experimental group (X and $\mathrm{T}$ ) at two time points ( $7 \mathrm{~d}$ and $30 \mathrm{~d})$ and control group were collected for RT2 Profiler PCR Array analysis (three rats per group). The Rat Inflammatory Cytokines \& Receptors $\mathrm{RT}^{2}$ Profiler PCR Array contains 84 key genes involved in mediating immune cascade reactions during inflammation. In 7d-X group, 56 key genes were upregulated comparing with control group (Figures 1(a)(d)), while in 7d-T group only 20 genes were upregulated (data not shown). Comparing with 30d-X group, 30 genes in $7 \mathrm{~d}-\mathrm{X}$ group were up-regulated (data not

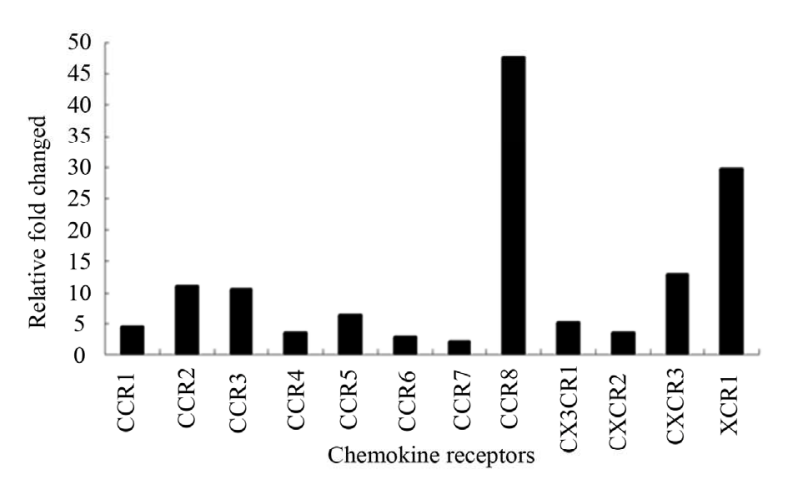

(b)

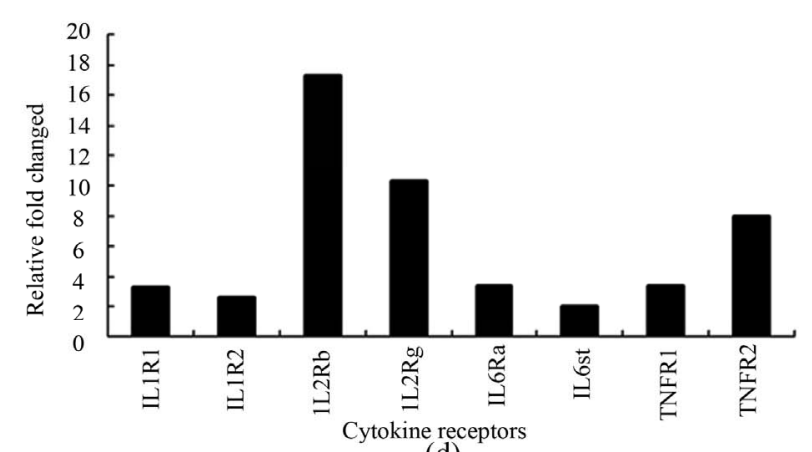

(d)

Figure 1. Inflammatory cytokines and receptors profile of buccal samples in $7 \mathrm{~d}-\mathrm{X}$ group OMT rat model. A representative result from three separate experiments is shown $(n=3)$. (a) Fold changes of upregulated chemokine mRNA expression level; (b) Fold changes of upregulated chemokine receptor mRNA expression level; (c) Fold changes of upregulated cytokine mRNA expression level; (d) Fold changes of upregulated cytokine receptor expression level. 
shown). While comparing with 30d-T group, only 12 genes in 7d-T group were up-regulated (data not shown).

As shown in Figure 1(a), CC chemokines including CCL2, CCL3, CCL4, CCL5, CCL6, CCL7, CCL9, CCL12, CCL17, CCL19, CCL20, CCL22 and CCL24, CXC chemokine consisting CXCL1, CXCL2, CXCL5, CXCL9, CXCL10 and CXCL11 were upregulated in rat buccal samples of $7 d-X$ group. In Figure 1(b), it showed that the expression of chemokine receptor covering CCR1, CCR2, CCR3, CCR4, CCR5, CCR6, CCR7, CCR8, CX3CR1, CXCR2, CXCR3 and XCR1 raised. Seventeen cytokine and eight cytokine receptors were also upregulated in $7 \mathrm{~d}-\mathrm{X}$ group, such as IFN- $\gamma, \mathrm{IL}-1 \alpha$, IL-1 $\beta$, Spp1, TNF, IL-1R1, IL-1R2, IL-2Rb and TNFR2 (Figures 1(c) and (d)).

\subsection{Upregulation of CXCL1 and CXCR2 Expression in Early Stage of Neutrophils Infiltration}

To further determine the expression of CXCL1 and CXCR2, rat buccal samples were collected from three experimental groups ( $\mathrm{X}, \mathrm{T}$ and $\mathrm{C}$ group) at two time points (Day 7 and Day 30). Real time PCR was employed to detect the mRNA expression of CXCL1 and CXCR2. As shown in Table 1, comparing with trauma group (T group) and control group (C group), CXCL1 mRNA expression of xenotransplantation group (X group) was significantly increased at day 7 but not at day 30 (Table 1). And comparing with $\mathrm{C}$ group, CXCR2 mRNA expression was also upregulated in $\mathrm{X}$ group at day 7 (Table 2). The protein expression of CXCL1 and CXCR2 obtain from ELISA are in accordance with the mRNA expression (Tables 3 and 4 ).

\subsection{Upregulation of CXCL1 and CXCR2 Expression Correlated with MPO}

For determination of the myeloperoxidase (MPO) expression in rat buccal sample and clarification of its

Table 1. CXCL1 mRNA expression level in rat buccal samples detected by RT-PCR $(10-3)\left({ }^{*} \mathrm{P}<0.05, \mathrm{n}=3\right)$.

\begin{tabular}{cccc}
\hline Group & Day 7 & Day 30 & P value \\
\hline $\mathrm{X}$ & $13.328 \pm 1.788$ & $1.346 \pm 0.208$ & $\mathrm{P}=0.010^{*}$ \\
$\mathrm{~T}$ & $1.827 \pm 0.151$ & $1.164 \pm 0.117$ & $\mathrm{P}=0.063$ \\
$\mathrm{C}$ & $2.683 \pm 0.837$ & & \\
$\mathrm{X}$ vs T & $\mathrm{P}=0.013^{*}$ & $\mathrm{P}=0.998$ & \\
$\mathrm{X}$ vs C & $\mathrm{P}=0.011^{*}$ & $\mathrm{P}=0.838$ & \\
T vs C & $\mathrm{P}=0.992$ & $\mathrm{P}=0.904$ & \\
\hline
\end{tabular}

$\mathrm{X}$, xenotransplantation group; $\mathrm{T}$, trauma group; $\mathrm{C}$, control group.
Table 2. CXCR2 mRNA expression level in rat buccal samples detected by RT-PCR $(10-3)\left({ }^{*} \mathrm{P}<0.05, \mathrm{n}=3\right)$.

\begin{tabular}{cccc}
\hline Group & Day 7 & Day 30 & P value \\
\hline $\mathrm{X}$ & $2.260 \pm 0.275$ & $1.294 \pm 0.093$ & $\mathrm{P}=0.144$ \\
$\mathrm{~T}$ & $1.252 \pm 0.044$ & $1.188 \pm 0.034$ & $\mathrm{P}=0.961$ \\
$\mathrm{C}$ & $0.991 \pm 0.190$ & & \\
$\mathrm{X}$ vs T & $\mathrm{P}=0.132$ & $\mathrm{P}=0.990$ & \\
$\mathrm{X}$ vs C & $\mathrm{P}=0.038^{*}$ & $\mathrm{P}=0.768$ & \\
T vs C & $\mathrm{P}=0.842$ & $\mathrm{P}=0.935$ & \\
\hline
\end{tabular}

$\mathrm{X}$, xenotransplantation group; $\mathrm{T}$, trauma group; $\mathrm{C}$, control group.

Table 3. CXCL1 protein expression level in rat buccal samples detected by ELISA (pg/mg) $\left(^{*} \mathrm{P}<0.05, \mathrm{n}=6\right)$.

\begin{tabular}{cccc}
\hline Group & Day 7 & Day 30 & P value \\
\hline $\mathrm{X}$ & $110.041 \pm 4.149$ & $19.452 \pm 1.695$ & $\mathrm{P}=0.144$ \\
$\mathrm{~T}$ & $21.193 \pm 1.432$ & $16.054 \pm 0.206$ & $\mathrm{P}=0.961$ \\
$\mathrm{C}$ & $23.406 \pm 1.083$ & & \\
$\mathrm{X}$ vs T & $\mathrm{P}<0.001^{*}$ & $\mathrm{P}=0.799$ & \\
$\mathrm{X}$ vs C & $\mathrm{P}=0.001^{*}$ & $\mathrm{P}=0.687$ & \\
T vs C & $\mathrm{P}=0.987$ & $\mathrm{P}=0.228$ & \\
\hline
\end{tabular}

$\mathrm{X}$, xenotransplantation group; $\mathrm{T}$, trauma group; $\mathrm{C}$, control group.

Table 4. CXCR2 protein expression level in rat buccal samples detected by ELISA (pg/mg) $\left({ }^{*} \mathrm{P}<0.05, \mathrm{n}=6\right)$.

\begin{tabular}{cccc}
\hline Group & Day 7 & Day 30 & P value \\
\hline $\mathrm{X}$ & $5.243 \pm 0.909$ & $2.695 \pm 1.179$ & $\mathrm{P}=0.435$ \\
$\mathrm{~T}$ & $1.286 \pm 0.112$ & $0.776 \pm 0.019$ & $\mathrm{P}=0.081$ \\
$\mathrm{C}$ & $0.312 \pm 0.028$ & & \\
$\mathrm{X}$ vs T & $\mathrm{P}=0.101$ & $\mathrm{P}=0.002^{*}$ & \\
$\mathrm{X}$ vs C & $\mathrm{P}=0.042^{*}$ & $\mathrm{P}<0.001^{*}$ & \\
T vs C & $\mathrm{P}=0.003^{*}$ & $\mathrm{P}=0.054$ & \\
\hline
\end{tabular}

$\mathrm{X}$, xenotransplantation group; $\mathrm{T}$, trauma group; $\mathrm{C}$, control group.

correlation with CXCL1-CXCR2 axis, MPO protein expression was tested by ELISA analysis. Results of correlation analysis are presented in Table 5 . A close correlation $(\mathrm{r}=0.862, \mathrm{P}=0.027)$ was observed in $\mathrm{X}$ group between MPO protein expression and that of CXCL1. A similar result was obtained between MPO protein expression and that of CXCR2 $(\mathrm{r}=0.853, \mathrm{P}=$ 0.031). However, in $T$ and $C$ group, no noticeable correlation was observed between protein expression of MPO and that of CXCL1 or CXCR2. 


\subsection{Downregulation of CXCL1-CXCR2 Axis Expression by FK506 Treatment}

Rats from X, T and C groups with or without FK506 treated were sacrificed at day 7 after surgery, protein expression of CXCL1 and CXCR2 were detected by ELISA assay. After treated with FK506, both CXCL1 and CXCR2 protein expression were significantly reduced in X group (Tables 6 and 7).

\section{DISCUSSION}

Traditionally, neutrophils are only regarded as the important innate immune cells comprising the first line of innate immunity, which migrate to the site of infection or inflammation for clearance of infectious particles. However, recent researches have highlighted that earlier concepts of activation of innate immune response and adaptive response separately should be considered outdated. As reviewed before, neutrophils not only emerged as innate immune cells, their activation also linked

Table 5. Correlation between MPO and CXCL1, CXCR2 expression level $\left({ }^{*} \mathrm{P}<0.05, \mathrm{n}=6\right)$.

\begin{tabular}{ccccc}
\hline Group & \multicolumn{2}{c}{ MPO and CXCL1 } & \multicolumn{2}{c}{ MPO and CXCR2 } \\
\hline & $\begin{array}{c}\text { correlation } \\
\text { coefficient (r) }\end{array}$ & P value & $\begin{array}{c}\text { correlation } \\
\text { coefficient (r) }\end{array}$ & P value \\
X & 0.862 & $0.027^{*}$ & 0.853 & $0.031^{*}$ \\
T & 0.657 & 0.157 & 0.741 & 0.092 \\
C & 0.649 & 0.351 & 0.915 & 0.085 \\
\hline
\end{tabular}

$\mathrm{X}$, xenotransplantation group; $\mathrm{T}$, trauma group; $\mathrm{C}$, control group.

Table 6. CXCL1 protein expression level in rat buccal samples in day 7 groups with and without FK506 treatment $(\mathrm{pg} / \mathrm{mg})\left({ }^{*} \mathrm{P}\right.$ $<0.05, \mathrm{n}=6$ ).

\begin{tabular}{cccc}
\hline Group & FK506 untreated & FK506 treated & P value \\
\hline $\mathrm{X}$ & $110.041 \pm 4.149$ & $67.277 \pm 2.439$ & $\mathrm{P}=0.001^{*}$ \\
$\mathrm{~T}$ & $21.193 \pm 1.432$ & $15.275 \pm 1.077$ & $\mathrm{P}=0.442$ \\
$\mathrm{C}$ & $23.406 \pm 1.083$ & $24.314 \pm 2.865$ & $\mathrm{P}=1.000$ \\
\hline
\end{tabular}

$\mathrm{X}$, xenotransplantation group; $\mathrm{T}$, trauma group; $\mathrm{C}$, control group.

Table 7. CXCR2 protein expression level in rat buccal samples in day 7 groups with and without FK506 treatment $(\mathrm{pg} / \mathrm{mg})\left(^{*} \mathrm{P}\right.$ $<0.05, \mathrm{n}=6$ ).

\begin{tabular}{cccc}
\hline Group & FK506 untreated & FK506 treated & P value \\
\hline $\mathrm{X}$ & $5.243 \pm 0.909$ & $1.109 \pm 0.063$ & $\mathrm{P}=0.046^{*}$ \\
$\mathrm{~T}$ & $1.286 \pm 0.112$ & $0.803 \pm 0.061$ & $\mathrm{P}=0.315$ \\
$\mathrm{C}$ & $0.312 \pm 0.028$ & $0.313 \pm 0.051$ & $\mathrm{P}=1.000$ \\
\hline
\end{tabular}

$\mathrm{X}$, xenotransplantation group; $\mathrm{T}$, trauma group; $\mathrm{C}$, control group. both innate immunity and adaptive immunity $[1,2]$. For example, upon their activation, neutrophils generated various chemotactic factors which attracted monocytes/ macrophages and dendritic cells (DCs) to the site of infection or inflammation. By inducing maturation of immature DCs and increasing expression of costimulatory molecules, neutrophils provided signals for induction of $\mathrm{T}$ cell immune response. The interaction between neutrophils and various innate immune cells (i.e. macrophages, DCs) and adaptive immune system ( $\mathrm{T}$ cells and $B$ cells] have been reported involved in several immune responses against various pathogens and tumor antigens $[1,2]$.

Since the involvement of chemokines and microenvironment of neutrophils recruitment in oral mucosa is unclear, in this study, PCR array was applied to our previously establishesd oral mucosal xenotransplant rat model, which was characterized by neutrophils infiltration [9]. The results showed that during early stage of neutrophils infiltration in oral mucosa, 56 genes were upregulated. Among these up-regulated genes, 19 of them were chemokines with different function in recruiting immune cells. CXCL1, CXCL2 and CCL3 which have been reported to induce a neutrophils influx; CCL2 (MCP-1), CCL12 (MCP-5), CCL3 (MIP-1 $\alpha$ ), CCL4 (MIP-1 $\beta$ ) and CXCL2 (MIP2-alpha) which were associated with monocytes and macrophages chemotactic activity, CXCL10 and CXCL11, CCL22 and CCL24, CXCL1 and CXCL2 which have been demonstrated to induce Th1, Th2 and Th17 T cell migration respectively were included in our PCR array profile [11-13]. In previous study, Inflammatory Cytokines and Receptors PCR array has been applied on other organ such as colorectum to assessing the stromal microenvironment and particularly, inflammatory activity within colorectal neoplastic lesions [14]. In sporadic adenomatous colonic polyps, Inflammatory cell infiltration is a key feature and is in association with characteristics of high malignant potential. The PCR array including several inflammatory cytokine genes CXCL1, CXCL2, CXCL3, CCL20, IL8, CCL23, CCL19, CCL21 and CCL5 has provided evidence of increased inflammation within pre-malignant colonic adenomas, which may allow potential mechanistic pathways in the initiation and promotion of early colorectal carcinogenesis [14]. To the best of our knowledge, our study is the first to applied Inflammatory Cytokines \& Receptors PCR Array on oral mucosa under inflammation. And our PCR array data provided the panorama of cytokines and chemokines involved in oral mucosa during neutrophil recruitment. Comparing with other scatter and sparse results, our result outline the profile of a fine-tune series of inflammatory mediator accompanied with the neutrophils infiltration in oral mucosa which may provide great hints to investigate the 
interaction between inflammatory mediator, immune cells and even innate and adaptive immune response in oral mucosa.

From our PCR array results, we noticed that the expression of chemokine CXCL1 and its receptor CXCR2 were up-regulated which was in consistent with influx of neutrophils in oral mucosa. In previous study, CXCL1CXCR2 axis has been reported to play a significant role in neutrophils chemotaxis in several diseases and different tissues or organs such as adenoviral keratitis, hemolytic transfusion reactions, rhinovirus infection induced neutrophilic airway inflammation, autoantibodymediated arthritis and cortical damage following closed head injury [4-8]. However, the correlation between CXCL1-CXCR2 axis and neutrophils recruitment in oral mucosa has not been reported. So after the determination of the CXCL1 and CXCR2 mRNA and protein expression in rat buccal mucosa, we chose MPO as a biomarker of neutruphil to investigate the correlation between CXCL1-CXCR2 axis and neutrophils infiltration. Myeloperoxidase (MPO) is a well-known enzyme mainly released by activated neutrophils, MPO levels in these cells range from $2 \%-5 \%$ of total cellular protein. So in experimental inflammation research, detection of active MPO is a widely used marker to monitor the extent of neutrophils influx in tissues [15-18]. Our results showed a closed correlation between MPO and CXCL1-CXCR2 axis expression, which strongly suggested that CXCL1 and its receptor, CXCR2, mediated neutrophils migration in oral mucosa. As far as we know, this study is the first to demonstrate that recruitment of neutrophils to oral mucosa are associated with CXCL1-CXCR2 axis expression. Neutrophils have been reported to play important roles in oral diseases such as periodontitis. In periodontal pathogenesis, neutrophils, which accumulate in the periodontal tissue where they are available to participate in tissue destruction, may be especially crucial during the transition from gingivitis to periodontitis. Relevant studies have demonstrated that defective neutrophils recruitment or function increases host susceptibility to experimentally induced alveolar bone loss [19]. Another critical roles of neutrophils worth our attention are their significant impact on tumorogenesis. It has been reported that products secreted from neutrophils have defined and specific roles in regulating tumor cell proliferation, angiogenesis, and metastasis in myxofibrosarcoma, bronchioloalveolar carcinoma, colon adenocarcinoma, gastric carcinoma and melanoma [20-22]. However, whether neutrophil infiltration also participates in the carcinogenesis progression of oral cancer has not been reported. If so, whether CXCL1-CXCR2 axis is associated with neutrophils migration in oral cancer is an interesting subject needs further study and it may be a promising biomarker and therapeutic target for antitumor therapy in the future.

In our previous study, it was shown that after Tacrolimus (FK506) treatment neutrophils infiltration was obviously diminished in oral mucosa, and the MPO protein expression was also decreased [9]. These results suggested that neutrophils were also one of FK506's targets besides T cells in oral mucosa. In fact, an increasing number of papers in several animal models and human disease were in consistent with our findings which suggested that FK506 not only inhibits the function of T cells but also the infiltration of neutrophils [23-27]. In rat focal cerebral ischemia, FK506 suppressed neutrophils infiltration by inhibiting NF-kB translocation and subsequent production of chemokines such as CXCL1 [23]. Similar mechanisms for FK506 have been proposed in a model of murine colitis model, where FK506 treatment inhibited neutrophils recruitment through suppression of CXCL1 and CXCL2 production [27]. After confirming the participation of CXCL1-CXCR2 axis in neutrophils recruitment, we further testify whether CXCL1-CXCR2 axis is FK506's target on neutrophils suppression. Our results demonstrated that after treated with FK506, both CXCL1 and CXCR2 protein expression were significantly reduced which were associated with the diminished neutrophils infiltration. These results provided great hints that CXCL1-CXCR2 axis may be one of the targets of FK506's suppression on neutrophils infiltration in oral mucosa. Furhter study on the mechanisms of FK506's inhibition on CXCL1-CXCR2 axis may explore the potential of FK506 as a means of anticancer therapy targeting tumor-associated neutrophils.

\section{CONCLUSION}

Inflammatory cytokines and receptors profiles presented in this study demonstrated that neutrophils infiltration in oral mucosa triggered a local inflammatory response followed by a fine-tune series of mediator such as cytokine and chemokine synthesis. Among the chemokines, CXCL1-CXCR2 axis made great contribution to neutrophils infiltration in oral mucosa. Further more, CXCL1CXCR2 axis may be the possible target underlying FK506's neutrophils suppressive properties.

\section{ACKNOWLEDGEMENTS}

This study was supported by National Natural Science Foundation of China (No. 91029712, 81272948 Bin Cheng), Scholarship for Outstanding Ph.D. candidates of Ministry of Education of China (520003191002, Tong Wu), Guangdong Translational Medicine Public Platform (4202037, Bin Cheng)

\section{REFERENCES}

[1] Borregaard, N. (2010) Neutrophils, from marrow to microbes. Immunity, 33, 657-670. 
http://dx.doi.org/10.1016/i.immuni.2010.11.011

[2] Kumar, V. and Sharma, A. (2010) Neutrophils: Cinderella of innate immune system. International Immunopharmacology, 10, 1325-1334.

http://dx.doi.org/10.1016/j.intimp.2010.08.012

[3] Gerard, C. and Rollins, B.J. (2001) Chemokines and disease. Nature Immunology, 2, 108-115. http://dx.doi.org/10.1038/84209

[4] Chintakuntlawar, A.V. and Chodosh, J. (2009) Chemokine CXCL1/KC and its receptor CXCR2 are responsible for neutrophil chemotaxis in adenoviral keratitis. Journal of Interferon \& Cytokine Research, 29, 657-666. http://dx.doi.org/10.1089/jir.2009.0006

[5] Jang, J.E., Hod, E.A., Spitalnik, S.L. and Frenette, P.S. (2011) CXCL1 and its receptor, CXCR2, mediate murine sickle cell vaso-occlusion during hemolytic transfusion reactions. Journal of Clinical Investigation, 121, 13971401. http://dx.doi.org/10.1172/JCI45336

[6] Nagarkar, D.R., Wang, Q., Shim, J., Zhao, Y., Tsai, W.C., Lukacs, N.W., et al. (2009) CXCR2 is required for neutrophilic airway inflammation and hyperresponsiveness in a mouse model of human rhinovirus infection. Journal of Immunology, 183, 6698-6707. http://dx.doi.org/10.4049/jimmunol.0900298

[7] Jacobs, J.P., Ortiz-Lopez, A., Campbell, J.J., Gerard, C.J., Mathis, D. and Benoist, C. (2010) Deficiency of CXCR2, but not other chemokine receptors, attenuates autoantibody-mediated arthritis in a murine model. Arthritis \& Rheumatism, 62, 1921-1932.

[8] Semple, B.D., Bye, N., Ziebell, J.M. and MorgantiKossmann, M.C. (2010) Deficiency of the chemokine receptor CXCR2 attenuates neutrophil infiltration and cortical damage following closed head injury. Neurobiology of Disease, 40, 394-403. http://dx.doi.org/10.1016/j.nbd.2010.06.015

[9] Wang, H., Tao, X.A., Xiang, J., Xia, J., Huang, Y. and Cheng, B. (2011) Neutrophils infiltration is early event of an oral mucosal xenotransplantation model. Medicina oral, Patología Oral y Cirugía Bucal, 16, e341-e347. http://dx.doi.org/10.4317/medoral.16.e341

[10] Tao, X., Huang, Y., Li, R., Qing, R., Ma, L. and Rhodus, N.L. (2007) Assessment of local angiogenesis and vascular endothelial growth factor in the patients with atrophic-erosive and reticular oral lichen planus. Oral Surgery, Oral Medicine, Oral Pathology, Oral Radiology, and Endodontology, 103, 661-669.

http://dx.doi.org/10.1016/j.tripleo.2006.05.023

[11] Mackay, C.R. (2001) Chemokines: Immunology's high impact factors. Nature Immunology, 2, 95-101. http://dx.doi.org/10.1038/84298

[12] Kobayashi, Y. (2008)The role of chemokines in neutrophil biology. Frontiers in Bioscience, 13, 2400-2407. http://dx.doi.org/10.2741/2853

[13] Mackay, C.R. (2008) Moving targets: cell migration inhibitors as new anti-inflammatory therapies. Nature Immunology, 9, 988-998. http://dx.doi.org/10.1038/ni.f.210

[14] McLean, M.H., Murray, G.I., Stewart, K.N., Norrie, G.,
Mayer, C., Hold, G.L., et al. (2011) The inflammatory microenvironment in colorectal neoplasia. PLoS One, 6, e15366. http://dx.doi.org/10.1371/journal.pone.0015366

[15] Segal, A.W. (2005) How neutrophils kill microbes. Annual Review of Immunology, 23, 197-223. http://dx.doi.org/10.1146/annurev.immunol.23.021704.11 $\underline{5653}$

[16] Lau, D. and Baldus, S. (2006) Myeloperoxidase and its contributory role in inflammatory vascular disease. Pharmacology \& Therapeutics, 111, 16-26. http://dx.doi.org/10.1016/j.pharmthera.2005.06.023

[17] van der Veen, B.S., de Winther, M.P. and Heeringa, P. (2009) Myeloperoxidase: Molecular mechanisms of action and their relevance to human health and disease. $\mathrm{An}$ tioxidants \& Redox Signaling, 11, 2899-937.

[18] Loria, V., Dato, I., Graziani, F. and Biasucci, L.M. (2008) Myeloperoxidase: A new biomarker of inflammation in ischemic heart disease and acute coronary syndromes. Mediators of Inflammation, 2008, Article ID: 135625. http://dx.doi.org/10.1155/2008/135625

[19] Nussbaum, G. and Shapira, L.J. (2011) How has neutronphil research improved our understanding of periodontal pathogenesis? Journal of Clinical Periodontology, 38, 49-59. http://dx.doi.org/10.1111/j.1600-051X.2010.01678.x

[20] Houghton, A.M. (2010) The paradox of tumor-associated neutrophils: fueling tumor growth with cytotoxic substances. Cell Cycle, 9, 1732-1737. http://dx.doi.org/10.4161/cc.9.9.11297

[21] Tazzyman, S., Lewis, C.E. and Murdoch, C. (2009) Neutrophils: Key mediators of tumour angiogenesis. International Journal of Experimental Pathology, 90, 222-231.

[22] Gregory, A.D. and Houghton, A.M. (2011) Tumor-associated neutrophils: New targets for cancer therapy. Cancer Research, 71, 2411-2416. http://dx.doi.org/10.1158/0008-5472.CAN-10-2583

[23] Pereira, R., Medeiros, Y.S. and Fröde, T.S. (2006) Antiinflammatory effects of Tacrolimus in a mouse model of pleurisy. Transplant Immunology, 16, 105-111. http://dx.doi.org/10.1016/j.trim.2006.04.001

[24] Furuichi, Y., Noto, T., Li, J.Y., Oku, T., Ishiye, M. and Moriguchi, A. (2004) Multiple modes of action of tacrolimus (FK506) for neuroprotective action on ischemic damage after transient focal cerebral ischemia in rats. Brain Research, 1014, 120-130. http://dx.doi.org/10.1016/j.brainres.2004.04.031

[25] Caproni, M., Torchia, D., Antiga, E., Terranova, M., Volpi, W., del Bianco, E., et al. (2007) The comparative effects of tacrolimus and hydrocortisone in adult atopic dermatitis: An immunohistochemical study. British Journal of Dermatology, 156, 312-319. http://dx.doi.org/10.1111/j.1365-2133.2006.07609.x

[26] Koshika, T., Hirayama, Y., Ohkubo, Y., Mutoh, S. and Ishizaka, A. (2005) Tacrolimus (FK506) has protective actions against murine bleomycin-induced acute lung injuries. European Journal of Pharmacology, 515, 169178. http://dx.doi.org/10.1016/j.ejphar.2005.03.042

[27] van Lierop, P.P., de Haar, C., Lindenbergh-Kortleve, D.J., 
Simons-Oosterhuis, Y., van Rijt, L.S., Lambrecht, B.N., et al. (2010) T-cell regulation of neutrophil infiltrate at the early stages of a murine colitis model. Inflammatory
Bowel Diseases, 16, 442-451.

http://dx.doi.org/10.1002/ibd.21073 